\title{
Supply and Consumption of Household Energy in Central Ethi- opia: The Case of Debre Berhan Town
}

\author{
Solomon Ayele Tadesse ${ }^{1 *}$, Demel Teketay ${ }^{2}$
}

${ }^{1}$ Department of Natural Resources Management, College of Agriculture and Natural Resource Sciences, Debre Berhan University, Debre Berhan, Ethiopia

${ }^{2}$ Botswana University of Agriculture and Natural Resources, Department of Crop Science and Production, Gaborone, Botswana

"Corresponding author: Solomon Ayele Tadesse, Debre Berhan University,Department of Natural Resources Management, College of Agriculture and Natural Resource Sciences, Debre Berhan, Ethiopia. Tel: +2511116815440; Fax: +2511116812065; Email: solomon.ayele1972@gmail.com

Citation: Tadess SA, Tketey D (2018) Supply and consumption of household energy in central Ethiopia: the case of Debre Berhan town, Curr Trends Forest Res: CTFR-104. DOI: 10.29011/CTFR-104.100004

Received Date: 12 December, 2017; Accepted Date: 05 February, 2018; Published Date: 12 February, 2018

\begin{abstract}
Due to deforestation and land degradation, domestic energy crisis emanated from complete dependency on biomass energy is becoming one of the serious environmental problems. The objectives of the study were to quantify the main local energy supply and also examine the household energy consumption pattern in Debre Berhan town, Ethiopia. We hypothesized that there is spatial and temporal variation of local energy supply to the town. We also expected that socio-economic variables affect the energy consumption pattern at a household level. Point censusing was carried out to determine the amount of local energy source brought into the town. Moreover, a structured questionnaire was developed and administered to a total of 117 households to collect information on domestic energy consumption pattern in the town. Our results revealed that the amount of fuelwood brought into the town significantly affected by spatial and temporal factors. Overall, the amount of fuelwood brought into the town from Dessie point of entry is higher than that of Addis Ababa point of entry. Moreover, the amount of domestic energy source entering the town during the market days is higher than that of the non-market days. The questionnaire survey results revealed that the main source of perceived energy for household consumption in the town in descending order was local, electrical and petroleum. The study suggested that there is a remarkable deficiency of energy supply to Debre Berhan town. We recommended that creating public awareness about natural resources conservation is crucial to alleviate energy crises in the town.
\end{abstract}

Keywords: Biomass Energy; Debre Berhan Town; Domestic Energy Consumption; Local Energy Supply

\section{Introduction}

Biomass fuels are the most important sources of energy in developing countries in general and Sub-Saharan Africa in particular. Leach and Mearns [1] noted that a large number of fuel wood and forest development projects and policies in those countries have been based on recommendations of the result of what are called "fuel wood gap" models, which usually start with rough estimates of fuel wood demand and supply to predict future excess demand and recommend such programs as afforestation and improved stove dissemination to fill the "gap".

The percentage of biomass fuels in the total energy consumption in Ethiopia is one of the highest in the world, accounting for over $90 \%$ of the total energy consumption in the country and about $99 \%$ in the rural areas. EFAP [2] claimed that the shortage of biomass fuels has been one of the major causes of deforestation and, subsequent, land degradation in Ethiopia. Moreover, due to the significant use of dung and crop residues as energy sources, rural energy is closely linked with land degradation, which is considered to be one of the most important environmental and economic problems. As a result, Bojo and Cassells [3] noted that the gross annual financial losses due to land degradation in the country represent about $3 \%$ of the agricultural GDP or about $2 \%$ of the country's GDP. Of this, Sutcliffe [4] claimed that about $98 \%$ has been estimated to be caused by nutrient losses due to the removal of dung and crop residues from cropland for use as energy sources, which otherwise could have been used as organic fertilizer. The problems of land degradation have continued to be severe in most parts of Ethiopia, and the large dependency of the 



104. DOI: $10.29011 /$ CTFR-104. 100004

majority of the population on biomass energy sources contributes its share to the problem.

In the Amhara National Regional State (ANRS), northern Ethiopia, biomass fuels provide $99 \%$ of the total domestic energy supplies, with $64 \%$ derived from woody biomass, $14 \%$ from crop residues and $21 \%$ from cow dung [5]. However, these regional figures concealed considerable local variations both in biomass fuel supply and consumption. In addition, there are temporal changes in these patterns in the face of changing socks of fuelwood and the opportunity costs in its collection or purchase.

Debre Berhan is a town found in North Shewa Administrative Zone of ANRS, which is situated in the high plateau about $130 \mathrm{~km}$ north of Addis Ababa. Its paved road, the high way to Mekele, is traveled by an endless stream of men and women on foot, donkeys loaded with enormous piles of hay, dried dung cake, eucalyptus branches, splitted wood, ancient buses and jangling horse-drawn two-wheel carts, which serve as taxis. However, the only trees in the town or surrounding countryside are those of eucalyptus, first planted almost 100 years ago during the massive national afforestation program initiated by Emperor Menelik II [6,7]. The people in the town as well as 13,000 farmers in the immediate area, live in poverty and perpetual energy crises. One of the many problems they share with the bulk of the people in the country is an acute shortage of fuel wood for cooking and heating [8].

Like the people in other parts of Ethiopia, most of the dwellers in Debre Berhan town and its surroundings dominantly use traditional fuels, such as wood, crop residues and animal dung for household energy consumption. Due to these reasons, Debre Berhan town and its surroundings have also been suffering from environmental degradation that emanated from loss of vegetation cover, crop residues and animal dung, mainly, because of the everincreasing demand for fuel wood. Despite the critical shortage of fuel wood, which has forced the people to use dung and agricultural residues to meet their desperate energy requirements that, in turn, aggravates the ongoing environmental degradation, studies focusing on determining the demand and supply of biomass energy from different sources in Debre Berhan is lacking. The information from such studies can contribute to the proper understanding of the ongoing energy crisis and making informed decisions as well as taking timely actions required to address the problems.

Therefore, the objectives of this study were to:

- Determine the main local sources of energy and quantify their daily amount of supply to Debre Berhan town; and

- to assess the household energy consumption pattern in the town.

To meet the objectives of the study, two hypotheses were tested:

(i) There is spatial, i.e., point of entry to the town, and temporal, i.e., market versus non-market days, variations of local fuelwood supply brought into Debre Berhan town; and

(ii) Socioeconomic variables, such as sex, age, family size, occupation type, livestock ownership, level of education, annual income and accessibility to various energy sources, i.e., biomass, electricity and petroleum, affect the energy consumption pattern at a household level in the town.

\section{Materials and Methods}

\section{Study Area}

The study was conducted in Debre Berhan town, North Shewa Administrative Zone, ANRS, Ethiopia, located at 9 40 'N and $39^{\circ} 30^{\prime} \mathrm{E}$ (Figure 1). The town covers an area of 18,081.95 ha and has an estimated total population of 110,000 people. It is composed of 10 kebeles, the lowest administrative structures in Ethiopia. The mean annual temperature and rainfall of the area are $6.6^{\circ} \mathrm{C}$ and $940 \mathrm{~mm}$, respectively. The area is situated at an altitude of $2,750 \mathrm{~m}$. The topography of the area covers 86,10 and $4 \%$ flat, plateau and mountainous terrains, respectively. The soil types of the area are, mainly, dominated by brown colored soil (personal communication with North Shewa Administrative Zone Office, April 21, 2015).

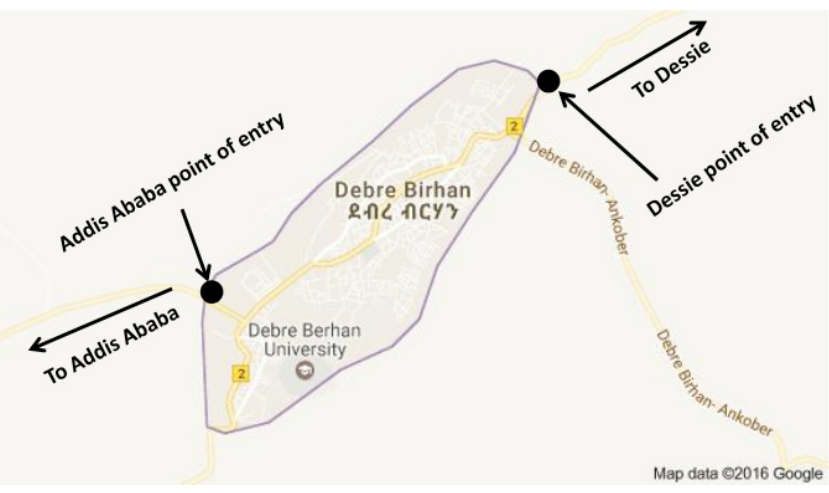

Figure 1: Map showing the location of Debre Berhan town. The two main points of fuelwood entry, i.e., Addis Ababa and Dessie points of entry, to Debre Berhan are shown. (Source: Google map data, 2016).

\section{Data Collection}

Initially, a preliminary survey was carried out in order to get better information about the study area and types of data to be collected. The data collection involved two methods, namely point census as well as household survey and market interview.

\section{Point Census}

The point census method was conducted at two main entry points to the town in order to collect data necessary to quantify the amount of local energy supply, i.e., splitted wood, dung, crop straw, leaves and charcoal brought to Debre Berhan town. These 


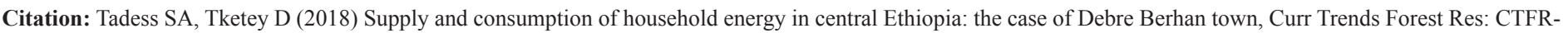
104. DOI: $10.29011 /$ CTFR-104. 100004

were the points of entry from Addis Ababa and Dessie cities, representing southern and northern Debre Berhan, respectively (see also Figure 1). At the two main points of entry to the town, the data enumerators counted the numbers of piles of splitted wood, dung, leaves, crop straw and charcoal brought by the local people during market and non-market days. Moreover, piles of each local fuelwood type (i.e., $n=50$ piles for each local fuelwood type) were systematically taken and weighed using a beam balance. This activity was important to quantify the mass of each type of local energy supply (i.e., kilograms of splitted wood, dung, leaves, crop straw and charcoal) brought into Debre Berhan town as shown in Figure 2 and 3. The data were collected during 20 market days, i.e., 10 days each from Addis Ababa and Dessie points of entry, as well as 20 non- market days, i.e., 10 days each from Addis Ababa and Dessie points of entry. This method was useful to get quantitative data that represent the effects of spatial (Addis Ababa and Dessie) and temporal (market versus non-market days) variations on the amount of local energy supply brought into the town. The data were collected between March and May 2015.

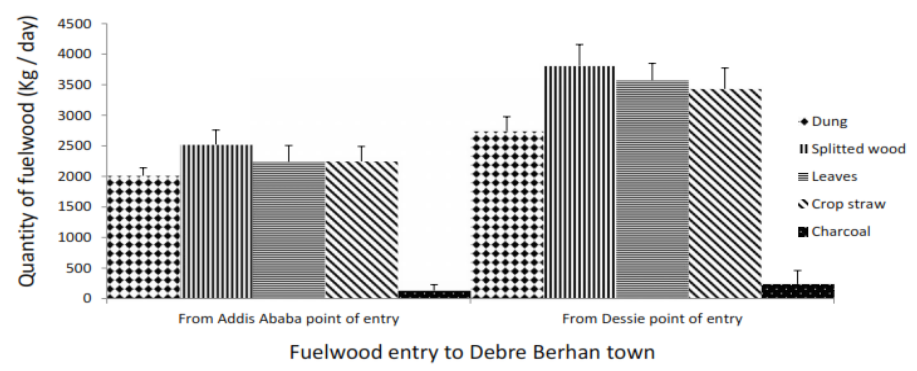

Figure 2: The effect of spatial variation, i.e., Addis Ababa and Dessie points of entry, on the daily amount of biomass energy brought into Debre Berhan town. The number of point counts $(\mathrm{N})$ included in this analysis was 20 each from Addis Ababa and Dessie points of entry. The bars showed mean +1 SE.

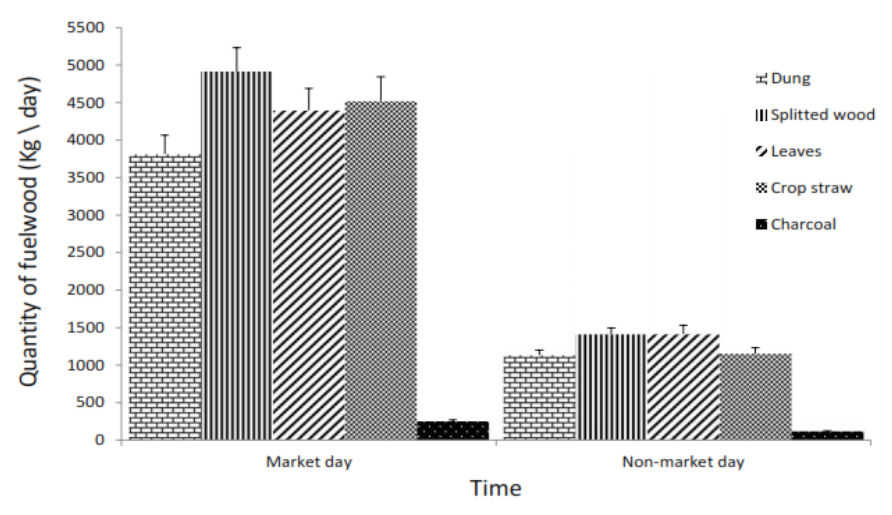

Figure 3: The effect of temporal variation, i.e., market and non-market days on the daily quantity of biomass energy brought into Debre Berhan town. The number of days $(\mathrm{N})$ included in this analysis were 20 each on market and non-market days. The bars showed mean $+1 \mathrm{SE}$.

\section{Household survey and market interviews}

A household survey involving administration of a structured closed- and open-ended questionnaire was conducted to collect data required to estimate the supply and consumption of household energy and identify other factors that determine patterns of household energy consumption in four kebeles of the town. The four study kebeles were randomly selected through a lottery system based on kebele numbers.

The questionnaire was developed by considering socioeconomic variables, such as sex, age, family size, occupation type, livestock ownership, level of education, annual income and accessibility to various energy sources, i.e., biomass, electricity and petroleum. The questionnaire was administered to a total of 117 households, representing 24 households from each kebele. In addition, 21 respondents were interviewed in the market area where there was selling and buying of dung, splitted wood, leaves, crop straw and charcoal. The data enumerators conducted the survey in May 2015 via direct house-to-house visits. The independent variables were derived from the following 8 questions: (i) sex, (ii) age, (iii) family size, (vi) occupation type, (v) livestock ownership, (vi) level of education, (vii) annual income and (vii) access to various energy sources. The dependent variables were derived from the following two statements: (i) 'the shortage of energy supply for household consumption in Debre Berhan town' and (ii) 'the consumption of various energy types, i.e., biomass, electricity and petroleum, at the household level in Debre Berhan town'.

\section{Data Analyses}

To test the effects of spatial variation, temporal variation and the interaction of spatial and temporal variations on the quantity of local energy types brought into Debre Berhan town, a Generalized Linear Model (GLM) was used with multivariate tests $[9,10]$. In the same analysis, univariate tests followed the multivariate ones for better interpretation of the multivariate results. The independent variables entered into the GLM included spatial and temporal variations. For the vector of dependent variables, the quantity of fuel types i.e., dung, splitted wood, leaves, crop straw and charcoal. A post hoc Tukey's HSD test was used for the multiple comparisons across fuel types.

Descriptive statistics was used to analyze the socioeconomic data and perceived major sources of energy at the household level in the town. To analyze and predict the effects of socioeconomic variables on the value of the dependent variables, a multiple linear regression model was employed $[9,11]$. For all the analyses, we defined the alpha value at 0.05 , and the analyses were performed using SPSS version 16.

\section{Results}

\section{Biomass Energy Supply}

The amount of biomass energy supply brought into Debre Berhan 


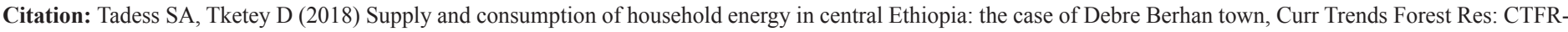
104. DOI: $10.29011 /$ CTFR-104. 100004

town was significantly affected by spatial and temporal factors. Specifically, the spatial variation (point of entry to the town) significantly affected the quantity of splitted wood, leaves and charcoal (Table 1). The temporal variation significantly affected the amount of splitted wood, dung, leaves, crop straw and charcoal (Table 1). However, spatial and temporal variations did not interact to affect the quantity of fuel types that were brought into the town.

\begin{tabular}{|c|c|c|c|c|c|c|c|}
\hline \multirow{2}{*}{ Factors } & \multirow{2}{*}{$\begin{array}{c}\text { Degree of } \\
\text { Freedom }\end{array}$} & Pillai's Trace Value & Dung & Splitted Wood & Leaves & Crop Straw & Charcoal \\
\cline { 3 - 8 } & 1 & 0.33 & NS & 4.16 & 5.02 & NS & 6.43 \\
\hline Spatial variation & 1 & 0.64 & 26.89 & 30.77 & 25.24 & 26.64 & 9.89 \\
\hline Temporal variation & 1 & 0.06 & NS & NS & NS & NS \\
\hline $\begin{array}{c}\text { Spatial } \times \text { temporal } \\
\text { variation }\end{array}$ & 1 & NS &
\end{tabular}

NS $=$ Not significant at $\mathrm{P}<0.05$. The total sample size $(\mathrm{N})$ considered for this analysis was 40 -point counts.

Table 1: Effects of spatial i.e., Addis Ababa versus Dessie points of entry, temporal i.e., market versus non-market days, and the interaction of spatial $\times$ temporal variations on the quantity of supply of biomass fuels brought into Debre Berhan town. Different statistical values were shown.

Overall, the amount of local energy supply brought into Debre Berhan town through Dessie point of entry was higher than that of Addis Ababa (Figure 2). Generally, the quantity of biomass energy supply brought into the town during market days was significantly higher than that on non-market days (Figure 3). Also, multiple comparisons across the quantities of biomass energy supply brought into the town during market and non-market days showed significant differences between dung, splitted wood, leaves, crop straw and charcoal (Figure 3). Generally, the largest amount of biomass fuel brought into the town during the market dayswas splitted wood (Figure 3).

\section{Supply and Consumption of Household Energy}

About half of the 117 respondents were males. The average age of the respondents was about 39 years. The average family size in a household was about 6 persons. A few of the respondents (about $28 \%$ ) were engaged in local liquor production and sales. Many of the respondents (about 78\%) owned livestock. Regarding the level of education, about $38 \%$ of the respondents went to primary school. The average annual income of the respondents was about 21,304.00 Ethiopian Birr (ETB), which was equivalent to 983.56 USD. The largest percentage (about $89 \%$ ) of the respondents had access to energy sources, such as dung, splitted wood, leaves, crop straw and charcoal. However, most of the respondents noted that they did not have access to electricity (about 72\%) and petroleum (about 99\%) energy sources (Table 2).

\begin{tabular}{|c|c|c|}
\hline Variables & Descriptive Results & $\begin{array}{c}\text { Proportion } \\
(\%)\end{array}$ \\
\hline \multirow{5}{*}{$\begin{array}{l}\text { Kebele and/or } \\
\text { village type }\end{array}$} & $09=24$ households & 20.51 \\
\hline & $08=24$ households & 20.51 \\
\hline & $07=24$ households & 20.51 \\
\hline & $01=24$ households & 20.51 \\
\hline & Market area $=21$ households & 17.96 \\
\hline $\begin{array}{c}\text { Total sample } \\
\text { size }(\mathrm{N})\end{array}$ & 117 households & \\
\hline
\end{tabular}

\begin{tabular}{|c|c|c|}
\hline \multirow{2}{*}{ Sex } & Male & 49.58 \\
\hline & Female & 50.42 \\
\hline Age & Mean $=38.48$ years; $S D=12.60$ & \\
\hline Family size & $\begin{array}{c}\text { Mean }=5.90 \text { persons; } \mathrm{SD}=5.76 \\
\text { persons }\end{array}$ & \\
\hline \multirow{8}{*}{ Occupation type } & Crop cultivation & 8.55 \\
\hline & Livestock rearing & 0.85 \\
\hline & Mixed farming & 8.55 \\
\hline & Pension & 5.13 \\
\hline & Government employee & 19.66 \\
\hline & Local liquor & 28.21 \\
\hline & Daily laborer & 5.98 \\
\hline & Merchant & 22.22 \\
\hline \multirow{2}{*}{$\begin{array}{l}\text { Livestock } \\
\text { ownership }\end{array}$} & Yes & 77.78 \\
\hline & No & 22.22 \\
\hline \multirow{6}{*}{ Education level } & MSc & 0.85 \\
\hline & Degree & 12.82 \\
\hline & Diploma & 6.84 \\
\hline & Primary education & 37.61 \\
\hline & Secondary education & 13.68 \\
\hline & Illiterate & 27.35 \\
\hline
\end{tabular}




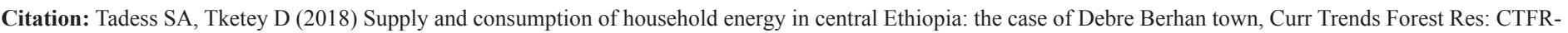
104. DOI: $10.29011 /$ CTFR-104. 100004

\begin{tabular}{|c|c|c|c|}
\hline Annual income & \multicolumn{2}{|c|}{$\begin{array}{c}\text { Mean }=21,304 \text { ETB; SD = } \\
12,910\end{array}$} & \multirow[b]{2}{*}{88.89} \\
\hline \multirow{6}{*}{$\begin{array}{l}\text { Accessibility to } \\
\text { various energy } \\
\text { sources }\end{array}$} & \multirow{2}{*}{ Local } & Yes & \\
\hline & & No & 11.11 \\
\hline & \multirow[t]{2}{*}{ Electricity } & Yes & 28.21 \\
\hline & & No & 71.79 \\
\hline & \multirow{2}{*}{ Petroleum } & Yes & 0.85 \\
\hline & & $\mathrm{No}$ & 99.15 \\
\hline
\end{tabular}

Table 2: Characteristics of samples and descriptive results.

As perceived by the local communities, the main sources of energy for household consumption in the town were, in descending order, biomass (dung, splitted wood, leaves, crop straw and charcoal), electricity and petroleum (Table 3 ).

The multiple linear regression model revealed that several socioeconomic variables significantly affected 'the shortage of energy supply for household consumption in Debre Berhan town'. As revealed from their coefficients, age $(\beta=0.63)$ and family size $(\beta=0.21)$ positively affected 'the shortage of energy supply for household consumption'. However, livestock ownership ( $\beta=$ $-0.59)$, annual income $(\beta=-0.31)$ and access to sources of energy $(\beta=-0.37)$ negatively affected 'the shortage of energy supply for household consumption'. Overall, the multiple linear regression model revealed that there is a 'shortage of energy supply for household consumption in Debre Berhan town' (about 49\% variance explained) (Table 4). More than half (about 59\%) of the respondents noted that one of the major reasons for the shortage of household energy consumption in Debre Berhan town was low annual income (Table 5).

\begin{tabular}{|c|c|c|c|}
\hline Variables & B & t-value & P-value \\
\hline Intercept & 0.73 & 1.86 & - \\
\hline Sex & 0.44 & 0.46 & 0.79 \\
\hline Age & 0.63 & $2.95^{* *}$ & 0.003 \\
\hline Family size & 0.21 & $2.28^{* *}$ & 0.03 \\
\hline Occupation type & -0.93 & 1.08 & 0.49 \\
\hline Livestock ownership & -0.59 & $3.58^{* *}$ & 0.001 \\
\hline Level of education & -0.64 & 0.7 & 0.64 \\
\hline Annual income & -0.31 & $3.45^{* *}$ & 0.001 \\
\hline Accessibility & -0.37 & $4.24^{* *}$ & 0.001 \\
\hline
\end{tabular}

aStandardized coefficients were reported; ** represents significance at the $95 \%$ confidence level; and ${ }^{b} R^{2}=0.69$ (Adj. $\left.R^{2}=0.49\right)$, $d f=7 ; F=$ 9.19, overall $\mathrm{P}<0.001$.

Table 4: Multiple linear regression model ${ }^{\text {a }}$ to predict the effects of socioeconomic variables on 'the shortage of energy supply for household consumption in Debre Berhan town'. '[The total sample size $(\mathrm{N})$ considered for this analysis was 117 households. The signs '+' and '-' indicate positive and negative changes, respectively, in shortage of energy supply for household consumption in the town.]

\begin{tabular}{|c|c|c|c|c|c|}
\hline Kebele & Sample size (N) & $\begin{array}{c}\text { Annual income } \\
(\%)\end{array}$ & Family size (\%) & $\begin{array}{c}\text { Access to sources } \\
\text { of energy }(\%)\end{array}$ & $\begin{array}{c}\text { Shortage of electrical } \\
\text { energy supply }(\%)\end{array}$ \\
\hline 1 & 24 & 79.17 & 62.5 & 50 & 37.5 \\
\hline 7 & 24 & 20.83 & 12.5 & 33.33 & 0 \\
\hline 8 & 24 & 66.67 & 58.33 & 33.33 & 0 \\
\hline 9 & 24 & 66.67 & 12.5 & 54.17 & 29.17 \\
\hline Market area & 21 & 61.9 & 19.04 & 52.38 & 42.86 \\
\hline Overall & 117 & $\mathbf{5 8 . 9 7}$ & 33.33 & 44.44 & 21.37 \\
\hline
\end{tabular}

Table 5: Major reasons perceived by local respondents for the shortage of household energy consumption in Debre Berhan town.

The multiple linear regression model also revealed that several socioeconomic variables affected the consumption of various energy sources at a household level in the town. As revealed from their coefficients, age $(\beta=0.94)$, family size $(\beta=0.83)$, livestock ownership $(\beta=0.39)$ and access to sources of energy $(\beta=0.68)$ had a positively significant effect on 'the consumption of biomass energy in Debre Berhan town'. However, occupation type $(\beta=-1.97)$, level of education $(\beta=-0.37)$ and annual income $(\beta=-0.84)$ negatively affected 'the consumption of biomass energy'. Overall, the multiple linear regression model revealed that socioeconomic variables had significant effect on 'the consumption of biomass energy in Debre Berhan town' (69\% variance explained) (Table 6). 


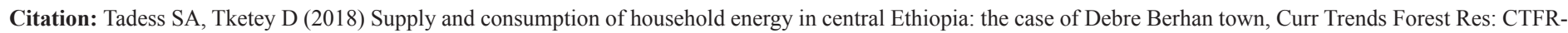
104. DOI: $10.29011 /$ CTFR-104. 100004

\begin{tabular}{|c|c|c|c|c|c|c|c|c|c|}
\hline \multirow{2}{*}{ Variables } & \multicolumn{3}{|c|}{${ }^{\mathrm{b} B i o m a s s}$ Energy Source } & \multicolumn{3}{|c|}{ 'Electrical Energy Source } & \multicolumn{3}{|c|}{ dPetroleum Energy Source } \\
\hline & $\mathbf{B}$ & t-value & P-value & B & t-value & P-value & $\mathbf{B}$ & t-value & P-value \\
\hline Intercept & 3.87 & 5.98 & - & -0.53 & 2.99 & - & -0.26 & 1.89 & - \\
\hline Sex & 0.34 & 0.77 & 0.46 & 0.66 & 0.75 & 0.37 & -0.57 & 0.89 & 0.35 \\
\hline Age & 0.94 & $3.98 * *$ & 0.001 & -0.36 & $2.68 * *$ & 0.004 & 0.28 & $2.89 * *$ & 0.002 \\
\hline Family size & 0.83 & $4.78 * *$ & 0.001 & 0.76 & $3.89 * *$ & 0.001 & -0.97 & $4.94 * *$ & 0.001 \\
\hline Occupation type & -1.99 & $5.78 * *$ & 0.001 & 0.297 & $4.49 * *$ & 0.001 & -0.78 & $3.58 * *$ & 0.001 \\
\hline Livestock ownership & 0.39 & $2.99 * *$ & 0.002 & -0.3 & $2.29 * *$ & 0.021 & -0.09 & 0.94 & 0.56 \\
\hline Level of education & -0.37 & $2.98 * *$ & 0.002 & 0.39 & $4.0^{*}$ & 0.001 & -0.58 & $3.94 * *$ & 0.001 \\
\hline Annual income & -0.84 & $4.83 * *$ & 0.001 & 0.94 & $4.59 * *$ & 0.001 & -0.95 & $5.07 * *$ & 0.001 \\
\hline Accessibility & 0.68 & $3.30 * *$ & 0.001 & 0.59 & $2.97 * *$ & 0.002 & -0.24 & 1.05 & 0.18 \\
\hline
\end{tabular}

${ }^{a}$ Standardized coefficient were reported; $* *$ represents significance at the $95 \%$ confidence level; ${ }^{b} \mathrm{R}^{2}=0.89\left(\right.$ Adj. $\left.\mathrm{R}^{2}=0.69\right), \mathrm{df}=7 ; \mathrm{F}=13.85$, overall $\mathrm{P}<0.001$; ${ }^{c} \mathrm{R}^{2}=0.91$ (Adj. $\left.\mathrm{R}^{2}=0.70\right)$, df $=7 ; \mathrm{F}=13.94$, overall $\mathrm{P}<0.001$; and ${ }^{\mathrm{d}} \mathrm{R}^{2}=0.81$ (Adj. $\mathrm{R} 2=0.62$ ), $\mathrm{df}=7 ; \mathrm{F}=12.78$, overall $\mathrm{P}<0.001$.

Table 6: Multiple linear regression model ${ }^{\text {a }}$ to predict the effects of socioeconomic variables on the consumption of various energy, i.e., biomassb, electricityc and petroleumd, at a household level in Debre Berhan town. ' $[$ The total sample size $(\mathrm{N})$ used in this analysis was 117 households. The signs ' + ' and '-' indicate positive and negative changes, respectively, in household energy consumption in the town].

As revealed from their coefficients, family size $(\beta=0.76)$, occupation type $(\beta=0.30)$, level of education $(\beta=0.39)$, annual income $(\beta=0.94)$ and access to sources of energy $(\beta=0.59)$ had positively significant effects on 'the consumption of electrical energy in Debre Berhan town'. However, age $(\beta=-0.36)$ and livestock ownership $(\beta=-0.30)$ had negatively significant effects on 'the consumption of electrical energy'. Overall, the multiple linear regression model revealed that socioeconomic variables had significant effect on 'the consumption of electrical energy in Debre Berhan town' (70\% variance explained) (Table 6).

As revealed from their coefficients, age $(\beta=0.28)$ had a positively significant effect on 'the consumption of petroleum energy in Debre Berhan town'. However, family size $(\beta=-0.97)$, occupation type $(\beta=-0.78)$, level of education $(\beta=-0.58)$ and annual income $(\beta=-0.95)$ had negatively significant effects on 'the consumption of petroleum energy'. Overall, the multiple linear regression model revealed that socioeconomic variables had significant effect on 'the consumption of petroleum energy in Debre Berhan town' (62\% variance explained) (Table 6).

\section{Discussion}

\section{Biomass Energy Supply}

Five major types of biomass energy were identified entering into Debre Berhan town. These were splitted wood, dung, crop straw, leaves and charcoal. The results revealed that the supply of biomass energy brought into the town is affected by spatial and temporal factors. Also, the majority of the fuelwood supply brought into the town was contributed by rural farmers whereas some of it was supplied by whole sellers. The supply of domestic energy to the town for household consumption was obtained, mainly, from nearby open access plantation forests, trees on farmlands, crop residues, dung and charcoal. Other studies also noted a similar source of biomass energy to various towns in different parts of Ethiopia [12-14].

In line with our first hypothesis, the results revealed that there was spatial variation in the quantity of fuelwood brought into the town depending on points of entry. Accordingly, the present study revealed that the amount of fuelwood brought into Debre Berhan town through Dessie point of entry was higher than that of Addis Ababa point of entry. One of the possible explanations for such a distinct variation in the supply of biomass energy brought into the town could be the difference in livelihood strategy of the rural people living in the adjacent area of the town. For example, the higher amount of biomass energy brought into the town through Dessie point of entry suggested that the nearby rural people heavily rely on the sale of various types of local fuelwood to manage their lives. The other possible explanation is that there may be higher quantity of biomass energy source or access to plantation forests or trees on farm lands for the rural poor who heavily depend on the sale of fuelwood in the vicinity of Dessie point of entry than in the surroundings of Addis Ababa point of entry. This is why the amount of splitted wood, leaves and charcoal brought into the town via the Dessie point of entry were all higher than that of the Addis Ababa point of entry.

In support of our second hypothesis, the quantity of fuelwood brought into the town during market days was higher than that of the non-market days. The results revealed that temporal variation significantly affected the amount of splitted wood, cow dung, leaves, crop straw and charcoal brought into the town and their quantities were all higher during the market days than that of the non-market days. This suggests that the rural people living in the adjacent area of Debre Berhan town may heavily depend on the sale of fuelwood that, in turn, may lead to the supply of higher amount of biomass energy during the market days than that of the non- 


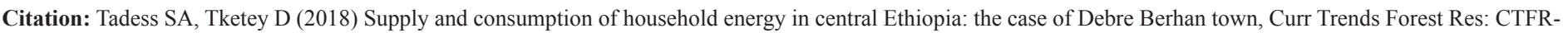
104. DOI: 10.29011/CTFR-104. 100004

market days. Generally, compared to the other types of biomass energy, the results showed that splitted wood had significantly the largest amount brought into the town during the market days, which may be attributed by its highest market price for the rural poor who heavily rely on the sale of fuelwood to support their lives. Even though sources of energy that are mostly biomass-based are available in unlimited amount in nature [15], the continuous and excessive supply of fuelwood to different towns from nearby rural areas may aggravate the rate of deforestation and subsequent land degradation [2], which, in turn, may result in the reduction of agricultural production and productivity [3]. Moreover, the excessive dependence of the majority of the people on biomass energy with very low use efficiency exacerbates the problem of deforestation and land degradation in Ethiopia $[16,17]$.

\section{Supply and Consumption of Household Energy}

Currently, over 2.5 billion people around the world depend on biomass fuels for cooking and heating [18-20]. Although all people have a legitimate right to and need for energy services, which are affordable, healthy, reliable and sustainable, energy issues are particularly challenging for developing countries where high energy costs exert tremendous pressure on fragile economies that have little capacity to adapt or change [21].

Previous research findings revealed that there is no change in the pattern of energy consumption where biomass fuels remained the principal energy resources in Ethiopia. According to the estimate made by Mekonnen [22] and WBISPP [23], more than $92 \%$ of the Ethiopia's current total energy demand is met using biomass fuels. The finding from this study revealed that about $89 \%$ of the total energy demand in Debre Berhan town is met by biomass fuel (Table 3). This showed that there is still high dependency on biomass fuels for household consumption in Debre Berhan town. The critical implication of high dependency on biomass fuel is its association with continuous transportation of high amounts of biomass energy into the town. This finding is in agreement with that reported by Anderson [24] who noted that consumption of fuelwood energy by households in Ethiopia is much higher than the total consumption of commercial energy for all purposes.

In line with our second hypothesis, the results revealed that households' energy supply and consumption pattern in Debre Berhan town were affected by several socioeconomic variables. For example, the results obtained through the multiple linear regression model suggested that there is a shortage of energy supply for household consumption in the town. Thus, our results revealed that the shortage of energy supply is significantly affected by age, family size, livestock ownership, annual income and access to sources of energy.

The increase in the shortage of energy supply for household consumption with age could be explained by the fact that, unlike young people, old people may be economically poor and/or physically less capable to travel long distance to acquire alternative source of energy to meet their household energy consumption. The results suggest that when family size increases, the shortage of energy supply for household consumption also increases. This is because the amount of energy required for cooking and heating purposes increases as family size in a household increases. However, the results suggested that the shortage of energy supply for household consumption decreases as livestock ownership increases. One of the possible reasons is that livestock can provide the household with dung that could be used as a source of energy for cooking and heating. Similarly, the study revealed that the shortage of energy supply for household consumption decreases as household annual income increases. This is because households with high annual income can afford to buy and use various sources of energy to meet their household energy demand. Moreover, the study revealed that the shortage of energy supply for household consumption decreases with the increase in access to different energy sources. This is because people will have different alternative sources of energy to meet their household demands when their access to energy sources increases.

The multiple linear regression model further revealed that several socioeconomic variables affected the consumption pattern of various energy sources, i.e., biomass, electricity and petroleum at a household level in Debre Berhan town.

The consumption of biomass energy increases with the increasing age, family size, livestock ownership and access to energy sources. Biomass energy source, such as dung, splitted wood, leaves, crop straw and charcoal are relatively cheaper than modern sources of energy (e.g. electricity and petroleum) for household consumption. Previous studies also noted that in Ethiopia, like in many developing countries, biomass fuels are the major sources of energy and the household energy consumption pattern is heavily dependent on these sources $[16,25]$. Almost all the rural and majority of the urban populations are dependent on biomass fuels, mainly, for cooking, because access to modern fuels is a constraint and the price is also unaffordable. Moreover, livestock can provide households with dung that could be used as a source of energy. Similarly, having access to energy sources provides the opportunity to alternative source of energy that helps meet household energy demands. This is why access to energy plays a central role in natural resources conservation and environmental protection [12].

However, the study revealed that the consumption pattern of biomass energy is negatively affected by occupation type, level of education and annual income. One of the possible reasons is that when people have different occupation types or their level of education increases or their annual income becomes high, they will have different options and outlooks to acquire different sources of 


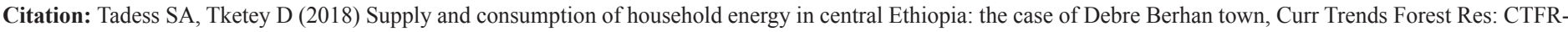
104. DOI: $10.29011 /$ CTFR-104. 100004

modern energy. As a result, their dependence on biomass energy decreases. This is why the people in the developed nations highly rely on modern energy. As a result, people may eagerly look for modern and efficient source of energy, such as electricity. A number of factors influence as to what sort of energy is used by which household, the most significant of them being the socio-economic status of households. For example, previous studies noted that households with higher socio-economic status, in terms of income and level of education, are expected to consume more energy, decrease using biomass fuels and increase the use of modern forms of energy [26]. Among other factors, family size of a household in terms of amount of energy and expenditure, access to various energy sources and household income could be considered as determining factors for domestic energy consumption.

The present study suggested that the consumption of electrical energy is positively correlated with family size, occupation, level of education, annual income and access to energy sources. When family size increases, the household energy consumption also increases. As a result, people may look for efficient source of energy to meet their household energy demands. In addition, when people have better occupation, or their level of education increases, or their annual income increases or they have better accessibility to different energy sources, they prefer to rely on modern and efficient source of energy like electricity. However, our study revealed that the consumption of electrical energy is negatively affected by age and livestock ownership. Unlike young people, old people may prefer traditional source of energy like local energy to meet their household energy demands because their traditional taboos may restrain them not to shift their energy usage from traditional to modern energy, such as electricity as revealed in this study. Moreover, livestock can provide households with dung that could be used as a source of energy for household consumption. As a result, people with livestock may not be interested to use modern energy like electricity for cooking and heating. They will be afraid of the costs of using electricity. Previous studies also noted that majority of urban populations are dependent on local energy mainly for cooking and heating, because access to modern energy is a constraint and the price is also unaffordable $[16,25]$.

The consumption of petroleum energy in Debre Berhan town was positively correlated with age. One possible explanation is that, unlike young people, old people used to rely on petroleum as a source of light in a household for long time in the past in different parts of Ethiopia, including Debre Berhan town. However, the consumption of petroleum energy was negatively correlated with family size, occupation type, level of education and annual income. There are a number of possible explanations for this. One of them is the cost of petroleum is increasing from time to time at an alarming rate and, as a result, people may not economically afford to use it as a source of energy for household consumption. The other possible explanation is that the smoke that pollutes the house when the petroleum is burnt during cooking and/or heating may not be tolerated by people when they have a better occupation or high level of education or high annual income because the emitted smoke due to petroleum burning could affect the health of the family.

Generally, the present study revealed that some of the respondents preferred biomass energy because of the low cost it had and associated with its acquiring method (e.g. free supply through selfcollection). About $47 \%$ of the respondents, who have low income in Debre Berhan town, have been using biomass energy because it is "the only option" that they have with respect to reliability and their living standards. Even though household income is the main factor that determines the type and amount of energy, the majority of the respondents in this study noted that they have been using local energy for the day-to-day cooking and heating activities in their households. Surprisingly, none of the respondents mentioned environmental reasons for choosing the source of energy, even those households who have been using electric energy for their cooking and heating activities. This suggests that respondents in the different study kebeles did not take environmental issues into consideration in their day-to-day household energy consumption while using local energy. In addition, traditional household energy is renewable, but the rate of consumption is much greater than the rate of production [12].

\section{Conclusions}

The study revealed that there is a continuous supply of biomass energy from the nearby rural areas to Debre Berhan town during market and non-market days, suggesting that there is high consumption of fuelwood in the town. Even though there is a continuous supply of biomass energy, the study showed that there were spatial (i.e., Addis Ababa and Dessie points of entry) and temporal (i.e., market versus non-market days) variations in biomass energy supply that is brought into the town. This suggested that the living condition of the rural poor people residing in the surrounding areas of Debre Berhan town is heavily reliant on the sale of biomass energy, i.e., splitted wood, dung, leaves, crop straw and charcoal. The results also suggested that majority of the households in Debre Berhan town are heavily dependent on biomass energy to meet their day-to-day cooking and heating activities. The main reason for this dependency is that there is a problem of reliable access to modern energy. Moreover, the cost of modern energy (e.g. electricity and petroleum) is relatively higher and unavoidable to the urban poor. Moreover, income level and family size may force the town dwellers to use biomass energy since the cost of modern energy is, generally, higher than the living standards of the poor people living in different towns of Ethiopia $[16,25]$. In addition, livestock ownership is also another reason that leads the urban dwellers in Debre Berhan town to use biomass energy (e.g. dung) as they can access it easily. 


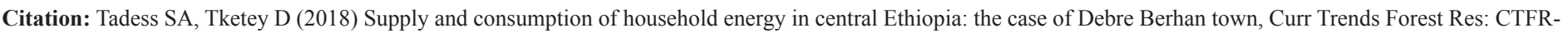
104. DOI: $10.29011 /$ CTFR-104. 100004

Scarcity of energy can lead to increased use of wood from forests, crop residues and animal dung as fuel. This compromises other uses, e.g. as fertilizer and animal fodder, and, in turn, leads to severe environmental degradation and reduction in agricultural output at a time when even greater production is expected in the sector. Moreover, indoor air pollution associated with traditional fuel consumption is a major health concern, especially for women and children when they heavily rely on biomass energy for cooking and heating activities. On top of this, combustion of crop residues and cow dung leads to lower inputs of soil organic matter, poor soil structure, lower retention of available nutrients in the crop root zone and reducing protection from erosion by heavy rainfall, exerting its negative impact on agricultural yields. Thus, the increase in biomass consumption, which increases partly with population growth, has an influence on the ecological balance and, consequently, lowers food production, resulting in poverty in the study site in particular and Ethiopia in general.

Based on the findings of the present study, the following recommendations are proposed. The exclusive dependency of the people on biomass energy for household consumption accompanied by high rates of population growth will worsen unless preventive measures are taken to improve natural resource conservation and management programs. Thus, public education about natural resources should be comprehensive enough ranging from the very practical definition to management of natural resources. This may, in turn, narrow the knowledge gaps that the local communities have about domestic energy consumption (biomass) with natural resource degradation. There should also be collaboration between bureau of education, environmental protection authority, energy sector, and bureau of agriculture and natural resources to disseminate energy know-how, i.e., awareness creation among the communities living in Debre Berhan town. In addition, dissemination of energy efficient technologies (e.g. energy saving stoves), creating job opportunities, family planning, strict government energy policy and provision of alternative energy (other than biomass energy) from the government with less taxation may decrease the bad consequences. Solutions to alleviate the unsustainable use of biomass energy, in turn, reduce environmental degradation. Other sources of energy, such as hydropower, wind power, solar energy and natural gas can potentially offer Ethiopia major economic development opportunity, thereby, reducing poverty and environmental degradation. Finally, we recommended that future research should also consider the season of the year since the supply and consumption of biomass energy in Debre Berhan town may vary depending on the season of the year.

\section{Acknowledgements}

Authors forward their gratitude to Debre Berhan University for the financial support. They extend their thanks to the local people residing in the different study kebeles of Debre Berhan town for sharing their fruitful ideas and abundant experiences about local household energy supply and consumption during the survey. They are grateful to the data enumerators for their assistance in the point census and survey.

\section{References}

1. Leach G, Mearns R (1988) Beyond the woodfuel crisis: people, land and trees in Africa. London: Earth scan.

2. EFAP (Ethiopian Forest Action Program), (1993) The challenges for development. Ministry of Natural Resources Development and Environmental Protection, Transitional Government of Ethiopia. Addis Ababa, Ethiopia.

3. Bojo J, Cassells D (1995) Land degradation and rehabilitation in Ethiopia: a re-assessment, AFTES working paper, Washington D. C, World Bank.

4. Sutcliffe J (1993) Economic assessment of land degradation in Ethiopia: a case study. National Conservation Strategy Secretariat, Ministry of Planning and Economic Development. Addis Ababa, Ethiopia.

5. AFAP (Amhara Forest Action Program) (1999) Challenges for forest development in Amhara National Regional State. Bureau of Agriculture, Bahir Dar, Ethiopia.

6. Farhana $\mathrm{H}$ (1984) A freelance journalist and principal English language news reader and communicator.

7. TeketayD(2000)FactsandexperienceoneucalyptusinEthiopiaandelsewhere: ground for making wise and informed decision. Walia.21: 25-46.

8. Ayele ZE (2008) Smallholder farmers' decision making in farm tree growing in the highlands of Ethiopia. Unpublished PhD Dissertation. Oregon State University, USA.

9. Zar JH (1999) Bio-statistical analysis. Prentice-Hall, London, United Kingdom, $4^{\text {th }}$ ed.

10. Tadesse SA, Kotler BP (2014) Effects of habitat, group-size, sex-age class and seasonal variation on the behavioral responses of mountain nyala (Tragelaphus buxtoni) in Munessa. Ethiopia, Journal of Tropical Ecology 30: 33-43.

11. Tadesse SA, Kotler BP (2016) Attitudes of local people towards the mountain nyala (Tragelaphus buxtoni) in Munessa, Ethiopia, African Journal of Ecology 54: 488-499.

12. Desta M, Mulugeta T (2002) Energy in Ethiopia: status, challenges and prospects. Proceeding of energy conference. Professional Associations' Joint Secretariat, UNCC, Addis Ababa, Ethiopia. 21-22.

13. Getachew $O$ (2002) Some socio-economic aspects of biomass energy in Ethiopia: status, challenges and prospects. Proceeding of energy conference. Professional Associations Joint Secretariat, UNCC, Addis Ababa, Ethiopia. March 21-22.

14. Alemu M, Tekie A (2003) Fuelwood situation in Ethiopia: pattern, trend and challenges. CIFOR occasional proceeding prepared at Goteborg, Germany. 39: 106-152.

15. EPA (Environmental Protection Authority) (2003) State of environment outlook: environment for development. Addis Ababa, Ethiopia.

16. Asress WG (2002) Overview of energy status and trends in Ethiopia: status, challenges and prospects. Proceeding of energy conference. Professional Associations Joint Secretariat, UNCC. Addis Ababa, Ethiopia. March 21-22. 
Citation: Tadess SA, Tketey D (2018) Supply and consumption of household energy in central Ethiopia: the case of Debre Berhan town, Curr Trends Forest Res: CTFR104. DOI: 10.29011/CTFR-104. 100004

17. UNDP / ESMAP/ (United Nations Development Program / Environmental Sustainability Management and Assessment Plan) (1996) Ethiopian energy assessment. The World Bank Report, Washington D. C, USA.

18. MME (Ministry of Mines and Energy) (2009) Energy resource potential of Ethiopia: energy development, follow-up and expansion development. Addis Ababa, Ethiopia.

19. IEA (2006) World energy outlook. IEA, Paris, France.

20. IUCN (2008) Energy, ecosystems and livelihoods: understanding linkages in the face of climate change impacts. Switzerland.

21. IUCN (2007) Energy, ecosystems and livelihoods initiative. IUCN, Gland, Switzerland.

22. Mekonnen K (1996) An overview to the energy situation in Ethiopia Ethiopian Rural Energy Development and Promotion Center, Ministry of Mines and Energy. Addis Ababa, Ethiopia.
23. WBISPP (Woody Biomass Inventory \& Strategic Plan Project) (2002) A strategic plan for the sustainable development, conservation and management of the woody biomass resources for Oromia regional state, Final Report. Addis Ababa, Ethiopia.

24. Anderson D (1986) Declining tree stocks in African countries. World Dev 14: 853-863.

25. Aklilu D (2008) Environmental education: a handout on the principles and practices of environmental education focus in Ethiopia. Addis Ababa University, Addis Ababa, Ethiopia.

26. Bereket K, Haregewoin D, Getnet A (1996) Petroleum pricing and taxation: the case of Ethiopia. Kenya and Malawi, AFREPREN 145. 